\title{
RELAÇÃO PEDAGÓGICA NO ENSINO PRÁTICO-REFLEXIVO: ELEMENTOS CARACTERÍSTICOS DO ENSINO DA INTEGRALIDADE NA FORMAÇÃO DO ENFERMEIRO ${ }^{1}$
}

\author{
Margarete Maria de Lima², Kenya Schmidt Reibnitz ${ }^{3}$, Daiana Kloh' ${ }^{4}$, Kênia Lara da Silva ${ }^{5}$, Fabiane Ferraz ${ }^{6}$
}

${ }^{1}$ Artigo extraído da tese - Relação pedagógica no ensino prático reflexivo como elemento para a formação do enfermeiro na perspectiva da integralidade, apresentada ao Programa de Pós-Graduação em Enfermagem (PEN) da Universidade Federal de Santa Catarina (UFSC), em 2015.

${ }^{2}$ Doutoranda do PEN/UFSC. Bolsista CNPq. Florianópolis, Santa Catarina, Brasil. E-mail: margaretelima2@gmail.com

${ }^{3}$ Doutora em Enfermagem. Docente do Departamento de Enfermagem da UFSC. Florianópolis, Santa Catarina, Brasil. E-mail: kenya@ccs.ufsc.br

${ }^{4}$ Mestranda do PEN/UFSC. Docente do Departamento de Enfermagem da UFSC. Florianópolis, Santa Catarina, Brasil. E-mail: daianakloh@gmail.com

${ }^{5}$ Doutora em Enfermagem. Professora da Escola de Enfermagem da Universidade Federal de Minas Gerais. Belo Horizonte, Minas Gerais, Brasil. E-mail: rosenisena@uol.com.br

${ }^{6}$ Mestranda do PEN/UFSC. Bolsista do CNPq. Florianópolis, Santa Catarina, Brasil. E-mail: olaferraz@yahoo.com.br

\section{RESUMO}

Objetivo: identificar os elementos da relação pedagógica no ensino prático-reflexivo que caracterizem o ensino da integralidade.

Método: pesquisa qualitativa, do tipo estudo de caso. Coleta de dados ocorreu de maio de 2013 a setembro de 2014, com oito docentes de disciplinas do eixo integrador dos quatro últimos semestres de um Curso de Graduação em Enfermagem. Utilizou-se a triangulação de técnicas para coleta de dados, análise documental, observação não participante e entrevistas individuais. Análise de dados guiada pela proposta operativa de Minayo.

Resultados: a relação pedagógica no Curso de Graduação em Enfermagem está fundamentada em elementos que potencializam o ensino da integralidade, trazendo para o contexto da formação exemplos da prática, conectando o que foi visto na teoria com o encontrado nos serviços de saúde e oportunizando um processo de reflexão para o estudante e para o docente.

Conclusão: os elementos da relação pedagógica no ensino prático-reflexivo que caracterizam a aprendizagem a partir do princípio da integralidade, durante a formação do enfermeiro, estão relacionados à conexão teoria e prática, ao desenvolvimento do talento artístico profissional e ao processo de reflexão na e sobre a ação. A relação pedagógica no curso está caminhando para formar profissionais competentes para atuar diante de situações incertas e conflituosas encontradas nos serviços de saúde.

DESCRITORES: Enfermagem. Educação superior. Integralidade em saúde. Docentes. Estudantes.

\section{THE PEDAGOGICAL RELATIONSHIP IN PRACTICAL-REFLEXIVE EDUCATION: CHARACTERISTIC ELEMENTS OF TEACHING INTEGRALITY IN NURSE EDUCATION}

\begin{abstract}
Objective: to identify elements of the pedagogical relationship in practical-reflexive teaching that characterize the teaching of integrality. Method: a qualitative research using a case study. Data collection took place between May 2013 and September 2014, with eight faculty members from the integrating axis of the last four semesters of a nursing undergraduate course. Triangulation techniques for data collection, documentary analysis, non-participant observation and individual interviews were used. Data analysis was guided by Minayo's operative proposal.

Results: the pedagogical relationship in nursing undergraduate course is based on elements that enhance the teaching of integrality, bringing context examples of practice to education, connecting what was seen in theory with that is found in health services and providing a reflection process for the student and teacher.

Conclusion: the elements of the pedagogical relationship in the practical-reflexive teaching that characterize the learning from the integrality principle during nurse education are related to the theory and practice connection, the development of professional artistic talent and to the reflection process on and about the action. The pedagogical relationship in the course assists in the education of professionals who are able to competently act in uncertain and conflicting situations found in the health services.
\end{abstract}

DESCRIPTORS: Nursing. Education, highr. Integrality in health. Faculty. Students. 


\section{RELACIÓN PEDAGÓGICA EN LA ENSEÑANZA PRÁCTICO-REFLEXIVA: ELEMENTOS CARACTERÍSTICOS DE LA ENSEÑANZA DE LA INTEGRALIDAD EN LA FORMACIÓN DEL ENFERMERO}

\section{RESUMEN}

Objetivo: identificar los elementos de la relación pedagógica en la enseñanza práctico-reflexiva que caractericen la enseñanza de la integralidad.

Método: investigación cualitativa y del tipo estudio de caso. La recolección de datos se realizó entre mayo del 2013 hasta septiembre del 2014 con ocho docentes de las disciplinas del eje integrador de los cuatro últimos semestres de un Curso de Graduación en Enfermería. Se usó la triangulación de técnicas para la obtención de datos, análisis documental, observación no participante y entrevistas individuales. El análisis de datos fue guiado por la propuesta operativa de Minayo.

Resultados: la relación pedagógica en el Curso de Graduación en Enfermería se fundamenta en elementos que potencializan la enseñanza de la integralidad, trayendo para el contexto de la formación los ejemplos de la práctica, conectando lo que fue visto en la teoría con lo encontrado en los servicios de salud y dando lugar a un proceso de reflexión para el estudiante y el docente.

Conclusión: los elementos de la relación pedagógica en la enseñanza práctico-reflexiva que caracterizan el aprendizaje a partir del principio de la integralidad, durante la formación del enfermero, están relacionados con la conexión teórica y práctica al desarrollo del talento artístico profesional y al proceso de reflexión en y sobre la acción. La relación pedagógica en el curso está caminando para formar profesionales competentes para actuar ante las situaciones inciertas y conflictivas encontradas en los servicios de salud.

DESCRIPTORES: Enfermería. Educación superior. Integralidad en salud. Docentes. Estudiantes.

\section{INTRODUÇÃO}

O ensino de enfermagem na graduação e pósgraduação tem ocupado posição fundamental no processo de modernização e no desenvolvimento da assistência prestada à população. Tem o papel de qualificar os profissionais para atender as múltiplas, e cada vez mais complexas, demandas dos serviços de saúde. ${ }^{1}$ Nesse sentido, necessitamos repensar a formação pautada em princípios pedagógicos que valorizem a totalidade do estudante em formação e da pessoa cuidada por este futuro profissional. ${ }^{2}$

A integralidade aplicada também na relação pedagógica é uma possibilidade que se vislumbra para uma formação que considera elementos além da racionalidade técnica, formando enfermeiros competentes tecnicamente, mas também comprometidos com valores sociais e humanos. Esta possibilidade aliada a um ensino prático-reflexivo dá subsídios para que os futuros enfermeiros consigam buscar alternativas diante de situações complexas encontradas no cotidiano dos serviços de saúde.

As situações incertas encontradas no campo da prática, na maioria das vezes, se apresentam como um caso único, que o profissional não pode tratar como um problema instrumental a ser resolvido com a aplicação de uma regra ou técnica que compõe sua bagagem de conhecimentos. Estas situações não são previstas em manuais, por isso, necessitam ser tratadas de forma competente com certo tipo de improvisação, inventando e testando estratégias situacionais produzidas pelo próprio profissional. ${ }^{3}$

Nesse contexto, os profissionais lançam mão de competências para resolver situações incertas e conflituosas, denominadas de talento artístico pro- fissional. Alicerçado em um conhecimento tácito, nem sempre é possível de descrevê-lo, mas está presente durante a execução da ação mesmo que não tenha sido pensado anteriormente, complementando o conhecimento científico e as técnicas dominadas pelos profissionais. ${ }^{3}$

Nesse sentido, a formação do enfermeiro, ao ser vivenciada nos contextos dos serviços de saúde, possibilitará ao estudante refletir sobre a articulação entre o aprendido na teoria com o encontrado no campo da prática, bem como manejar situações reais e concretas, capacitando-o para assistir o ser humano na sua integralidade.

Salienta-se que o movimento de transformação no ensino tem instigado o desenvolvimento de pesquisas sobre a formação do enfermeiro, no entanto, encontram-se lacunas na produção do conhecimento que investigue a relação pedagógica nos cursos de enfermagem, ainda que esta seja o pilar fundamental de um ensino ancorado na prática reflexiva e no princípio da integralidade.

A integralidade, princípio norteador do Sistema Único de Saúde (SUS), deve orientar a prática dos profissionais de saúde. Contudo, percebe-se que este princípio tem sido aplicado quase que exclusivamente no cuidado à saúde, cuja aplicação tem apresentado limitações. A formação dos profissionais de saúde na perspectiva da integralidade requer que este princípio seja considerado também na relação pedagógica. ${ }^{4}$

Na formação do enfermeiro, a relação pedagógica é estabelecida com a intencionalidade de construir conhecimentos, de ensinar e aprender e refletir sobre as práticas vivenciadas durante o curso. Envolve uma 
rede de elementos que estão relacionados à instituição, ao professor, ao estudante, aos profissionais e usuários dos serviços de saúde envolvidos na formação. Diante disso, buscou-se identificar os elementos da relação pedagógica no ensino prático-reflexivo que caracterizem o ensino da integralidade.

\section{MÉTODO}

Estudo qualitativo, do tipo estudo de caso único, realizado em um curso de graduação de enfermagem de uma universidade pública do Sul do Brasil, que busca desenvolver uma educação crítica, criativa e reflexiva dos discentes.

Participaram da pesquisa oito docentes de disciplinas do eixo integrador (disciplinas que abordam o cuidado profissional em enfermagem) dos quatro últimos semestres do curso. Foram sorteados dois participantes de cada disciplina de um universo de 20 docentes. Como critérios de inclusão dos participantes, foram considerados: vínculo efetivo docente na instituição de ensino escolhida; atuação de mais de dois anos de exercício na docência; vivência institucional com atividades teóricas e teórico-práticas.

Utilizou-se a triangulação de técnicas para coleta de dados, a qual envolveu análise documental, observação não participante e entrevistas individuais. A coleta de dados foi realizada no período de maio de 2013 a setembro de 2014 e iniciou buscando informações nos planos de ensino das disciplinas do eixo integrador. Este processo foi uma valiosa fonte de informações, pois propiciou uma primeira aproximação com o contexto do curso de Graduação em Enfermagem estudado.

O segundo momento da coleta de dados foi a realização de 85 horas de observação em 28 momentos de ensino-aprendizagem dos docentes participantes da pesquisa, distribuídas em atividades teóricas, atividades teórico-práticas, estágio supervisionado e orientação de trabalho de conclusão de curso. Os dados das observações foram registrados em um diário de campo, contendo descrição da realidade e elementos da relação pedagógica no ensino prático reflexivo. Visando a respeitar o anonimato dos participantes, os planos de ensino foram identificados pelas letras PE (plano de ensino), e as observações foram identificadas pela letra $\mathrm{O}$ (observação), seguido da letra $\mathrm{D}$ (docente) e pelo número destinado a cada participante, acrescidos pelas letras $\mathrm{CT}$ de contexto teórico e $\mathrm{CP}$ de contexto da prática (OD1CT, OD1CP... OD8CT, OD8CP).

As entrevistas foram realizadas após a finalização das observações, no intuito de complementar as informações relacionadas aos documentos e às observações, contribuindo para compreender em profundidade a relação pedagógica no curso pesquisado. Foram gravadas em mídia digital e, após, transcritas na íntegra. Os depoimentos das entrevistas foram identificados com a letra $\mathrm{E}$ (entrevista) e com letra $\mathrm{D}$ (docente), seguidas por número distribuído aleatoriamente pela pesquisadora (ED1, ED2, ED3...ED8).

Para analisar os dados, utilizou-se a proposta operativa, descrita em dois momentos: fase exploratória da investigação e fase interpretativa dos dados. Primeiramente, foi realizada a leitura horizontal e exaustiva das informações oriundas da análise documental, observação e entrevista, estabelecendo uma relação interrogativa com os dados e buscando coerência interna das informações. ${ }^{5}$ No segundo momento, foi realizada a leitura de cada subconjunto e do conjunto em sua totalidade, separando os temas e categorias, colocando as partes semelhantes juntas, tentando perceber as conexões entre elas, e armazenando em códigos.

As ideias centrais deram origem à primeira etapa de codificação. Em seguida, a imersão e aprofundamento das informações obtidas na primeira codificação, realizada através da leitura linha por linha, buscando coerências e incoerências na triangulação das informações e recortando novamente as informações estruturaram as categorias de análise.

A pesquisa foi desenvolvida de acordo com os princípios éticos exigidos na Resolução n.466/2012. O projeto foi aprovado no Comitê Ética em Pesquisa com Seres Humanos da Universidade Federal de Santa Catarina, sob o CAAE n. 13975513.9.0000.0121.

\section{RESULTADOS}

A relação pedagógica no curso de graduação em Enfermagem fundamenta-se em elementos que potencializam o ensino da integralidade, trazendo para o contexto da formação exemplos da prática, conectando o que foi visto na teoria com o encontrado nos serviços de saúde e oportunizando um processo de reflexão para o estudante e para o docente. Esses elementos do ensino prático-reflexivo estão representados nas seguintes categorias: Aproximação com o contexto profissional: um elemento fértil para conectar teoria e prática na formação do enfermeiro para a integralidade; Reflexão na ação e sobre a ação como elementos potencializadores do ensino da integralidade na relação pedagógica; Talento artístico profissional: habilidades e performances do ensino na perspectiva da integralidade. 


\section{Aproximação com o contexto profissional: um elemento fértil para conectar teoria e prática na formação do enfermeiro para a integralidade}

Os achados do estudo indicaram que a aproximação e reflexão sobre o contexto dos serviços é um elemento do curso analisado. Nos planos de ensino das disciplinas, foi possível identificar elementos que potencializam essa aproximação.

O entrelaçamento da teoria e prática ocorre no contexto da sala de aula, com participação de profissionais do serviço e com aproximação com os campos onde as atividades teórico-práticas serão desenvolvidas [...] no cenário da prática assistencial mediante observação e atuação do estudante no campo das atividades teórico-práticas (PED1D2). Os estudantes possuem atividades no campo da prática que têm como objetivo comparar o preconizado na literatura com o realizado na prática (PED5D6).

Destacamos que, mesmo que não esteja descrito em todos os planos de ensino como ocorre a relação entre teoria e prática, existe um movimento por parte dos docentes que visa a aproximar o estudante da realidade do serviço, trazendo suas experiências da prática e incluindo os profissionais dos serviços neste debate. Esta articulação, ao ocorrer em aulas teóricas, desperta o interesse do estudante sobre a temática debatida, favorecendo o questionamento e a reflexão sobre as vivências da prática durante a formação.

Eu tento trazer os exemplos das minhas experiências e aquilo que a gente tem de mais presente no cotidiano da nossa atividade, tudo que eu já tive enquanto profissional de campo e agora como professora. [...] $O$ estudante grava diferentes formas de aprendizado e os exemplos práticos ajudam bastante o estudante a compreender (ED6).

O desafio do docente intensifica-se para conectar a teoria com a prática, porque nem sempre o estudante consegue estabelecer a relação do que foi visto na academia com o que é encontrado na prática, sendo um limitador o fato de que muitas vezes o docente não acompanhou o estudante durante o conteúdo teórico.

[...] professor precisa sensibilizar o estudante para equilibrar teoria e prática. A teoria tem que orientar a prática e a prática tem que refazer a teoria, num processo permanente de reflexão sobre a prática você teoriza e a partir disso você melhora a sua prática (ED5).

As situações vivenciadas na prática são ponto de partida para a discussão [...] professor faz articulação do texto de acolhimento com o acolhimento desenvolvido por uma aluna na unidade básica de saúde, trazendo contribuições para a prática (OD3CP).

\section{Reflexão na ação e sobre a ação como elementos potencializadores do ensino da integralidade na relação pedagógica}

Os achados demonstram que, tanto o estudante, quanto o docente vivenciavam momentos de conhecer e refletir na ação, sem que necessariamente progredissem para as demais etapas da reflexão (reflexão sobre a ação e reflexão sobre a reflexão na ação) na relação pedagógica.

Campo da prática com momentos ricos para a reflexão e sobre a ação. Durante coleta de exame preventivo de câncer de colo de útero aluna apresenta dificuldade em localizar o colo, professora auxilia, mas não estimula o processo de reflexão da estudante durante e após o procedimento (OD4).

Contudo, existe um movimento por partes de alguns docentes em avançar no conhecimento da ação para a reflexão na e sobre a ação, estimulando que o estudante reflita enquanto realiza o cuidado de enfermagem, e posteriormente a este.

Às vezes eu discuto, no momento, se a pergunta veio e eu me sinto segura ou mesmo insegura [...] às vezes eu consigo até conversar e refletir com eles junto, se é uma coisa que não precisa eu ir atrás, mas, se for uma coisa que realmente eu não sei, ou que seja uma coisa ética que às vezes a gente pode conseguir resolver numa conversa, mas, se não, eu vou a trás sime trago para os estudantes (ED7).

[...] às vezes, no mesmo dia a gente não consegue resgatar as coisas que ocorreram. Eu tenho como prática no dia seguinte, quando a gente tá entrando no campo de novo, a gente retoma algumas situações que foram vivenciadas no dia anterior (ED8).

Os resultados apontam que os docentes refletem sobre suas ações pedagógicas, estabelecendo um diálogo entre o pensar e o fazer, caracterizando a etapa de reflexão na e sobre a ação. A reflexão presente sobre a reflexão na ação dá início a um processo dialógico de pensar e fazer através do qual docente e estudante podem tornar-se habilidosos para determinada ação. Isso também se aplica ao cuidado em enfermagem. Pensar a integralidade na aprendizagem reflexiva implica em fazer um exercício sobre como sua aplicação tem ocorrido durante os momentos de ensino -aprendizagem; entendido não somente na relação da academia com o usuário do sistema de saúde, mas também na relação entre academia-academia, representada por professor e estudante.

A gente tem que estar refletindo e avaliando a nossa prática, porque, muitas vezes, a gente planeja de uma forma uma atividade com o estudante, e às vezes não foi o esperado, não surtiu o resultado que a gente imaginava 
pra despertar a curiosidade, o interesse, que é a busca do conhecimento do estudante (ED1).

Para ensinar integralidade o estudante precisa se ver como pessoa, como que ele responde às suas necessidades. Depois ele no contexto profissional, como ele atende essa demanda quando chega a ele. A realidade do estudante é ponto inicial para discutir a integralidade, como cidadão e como enfermeiro (ED3).

Os depoimentos dos docentes permitiram compreender a existência de uma relação pedagógica centrada no aprendizado do estudante como profissional e como pessoa. Este olhar para além do processo de aquisição de conhecimentos e habilidades na formação do enfermeiro indica que este sujeito em formação é percebido em sua integralidade. Todavia, considerar essa perspectiva implica em abertura do docente para entender o tempo de aprendizagem e as dificuldades dos estudantes. Este processo é permeado de desafios em decorrência da postura adotada pelo estudante e pelo docente.

Este olhar, que no primeiro momento pode parecer simples, torna-se complexo à medida que o estudante avança no curso, pois se espera que este já tenha adquirido conhecimentos em outras disciplinas e almeja-se que ele já desempenhe uma atuação bem próxima da sua profissão.

Tem o estudante que não se sente seguro, ele desestabiliza, não está na hora de chegar e assumir uma unidade, ele ainda não está apto e ele chegou lá [...] Tem estudantes que não têm compromisso [...] eu vou estar junto e nós vamos acompanhar. [...] É quando mais me cansa, porque eu vou todo dia até ele sentir que tem alguém ali, que a coisa tá apertada mesmo [...] vocêtem que fazer isso, onde está a sua dificuldade, vamos trabalhar juntos, o que eu tenho que olhar, que você tem que crescer, o que eu estou esperando de você hoje e o que eu espero de você ao final (ED6).

A preocupação do docente de que o estudante tenha atitudes que estejam de acordo com o preconizado no exercício do enfermeiro mostra que a relação pedagógica se volta para formar profissionais para atuar competentemente nos serviços de saúde e, principalmente, que sejam capazes de resolver situações incertas e conflituosas da prática. Esta habilidade pode ser adquirida com o desenvolvimento do processo de reflexão na ação e sobre a ação durante a própria formação.

\section{Talento artístico profissional: habilidades e performances do ensino na perspectiva da integralidade}

As manifestações do talento artístico profissional são potenciais para permitir a reflexividade na formação com a perspectiva da integralidade. Preparar os estudantes para adquirem essa performance e respeitar seu tempo de aprendizagem para o talento artístico estão presentes na atuação de alguns docentes quando estão no campo da prática.

Experiência negativa da aluna diante de uma situação incerta/conflituosa (entendimento equivocado dos agentes comunitários de saúde sobre dinâmica da reunião conduzida pelos estudantes) contribuiu para que aluna refletisse que adquiriu habilidade/performance na relação com equipe de enfermagem (OD5CP).

Tem que ter cuidado para não esperar que os estudantes adquiram competências que vão além das esperadas na disciplina, respeitando o momento que ele está no processo de formação (ED8).

Contudo, os achados revelaram que ainda há pouco estímulo para o desenvolvimento do talento artístico profissional tanto em sala de aula quanto no campo da prática, mesmo nas situações onde seria possível a abordagem dessa competência.

No campo da prática, a aluna faz algo diferente do preconizado nos manuais. Professora não critica, mas orienta a fazer como preconizado. [...] Situações incertas e conflituosas no campo da prática são pouco exploradas pelo docente (OD1CP).

Quando a técnica não está tão correta, mas que não infira em risco, tem que revisar técnica, mostro onde que estão as questões pra ele, pra que ele faça a correção (ED4).

Embora exista a fragilidade de explorar o talento artístico no campo da prática, há sinais que ainda no campo discurso tal expectativa é presente. O docente afirma que, durante a formação, o estudante precisa aprender a lidar com as diferenças entre o aprendido em sala de aula e o encontrado na prática, necessitando para isso adquirir habilidades e competências para o desenvolvimento da criatividade para agir em situações incertas e conflituosas.

Estudante precisa aprender a trabalhar com a diversidade e diferenças do aprendido em sala de aula e do que ocorre no campo da prática. É um aprendizado novo para o estudante onde ele vai aprender a flexibilizar e improvisar o cuidado. Ele como profissional vai precisar usar essa criatividade, essa flexibilidade pra agir nas situações que são inesperadas (ED1).

Manejar as demandas do campo da prática durante a formação do enfermeiro gera no docente a sensação de que a relação pedagógica ocorre em um espaço que tem governabilidade limitada, entre o que precisa ser aprendido na formação e a abertura que o campo fornece para resolver determinadas situações incertas e conflituosas.

A inserção na realidade, ao mesmo tempo que pode 
criar possibilidades para o desenvolvimento do talento artístico, também limita, pois ao estudante e professor são membros externos à equipe, e a capacidade de atuação de ambos está em uma margem muito estreita e sensível, pois dependendo da condução pode implicar em perda do campo de estágio (ED5).

As habilidades e performances do talento artístico entrelaçam com o princípio da integralidade do cuidado, pois, não podemos prever as demandas incertas e conflituosas que vamos encontrar no cotidiano dos serviços. O cuidar na perspectiva da integralidade é atender a demanda de quem procura o serviço de saúde, mediante uma prática reflexiva tanto do professor como do estudante, desde o momento em que ocorre a prestação de cuidado até a construção de novas possibilidade de cuidar na perspectiva da integralidade.

\section{DISCUSSÃO}

Os achados do estudo indicam que a aproximação e reflexão sobre o contexto dos serviços é um elemento do curso analisado. Evidenciou-se nos planos de ensino que existem elementos que potencializam a aproximação com o contexto dos serviços de saúde. Todavia, o documento sozinho não confere validade a essa aproximação de contextos, cabendo ao docente colocar em prática, por meio da relação pedagógica, a reflexão sobre o mundo da academia e as demandas encontradas no serviço.

No curso pesquisado, a conexão entre mundo da academia e do trabalho é o pressuposto fundamental na formação do enfermeiro, e condição para o desenvolvimento de um ensino prático-reflexivo na perspectiva da integralidade. No entanto, a articulação ensino e serviço necessita ser ancorada em um processo reflexivo que seja entrelaçado à realidade do serviço e não paralelo a esta. ${ }^{6}$

A universidade compete à responsabilidade de formar estudantes reflexivos, que consigam resolver as situações incertas da prática, respondendo as necessidades de saúde da população e da própria enfermagem como profissão. ${ }^{7}$ Quando encontramos uma situação dicotômica a esta, ou seja, um ensino desvinculado de uma prática reflexiva, temos como resultado uma formação incompatível com as demandas da sociedade e do serviço. ${ }^{8}$

O entrelaçamento entre teoria e prática é um desafio para o docente participante deste estudo, pois necessita encontrar alternativas metodológicas, para que o discente reflita sobre a realidade encontrada nos serviços. A inserção de profissionais dos serviços nas aulas teóricas, a descrição de exemplos vivenciados na prática do docente e a experiência da prática como ponto de partida para a discussão teórica são estratégias metodológicas para estimular a reflexão do discente. Neste sentido, acredita-se que relação pedagógica é guia mestra quando se trabalha numa perspectiva de um ensino prático-reflexivo.

A metodologia utilizada pelo professor é facilitadora do processo de ensino-aprendizagem ao relacionar teoria e prática, contribuindo para que os estudantes façam este entrelaçamento. ${ }^{9}$ A utilização de experiências reais e a inserção da aprendizagem em situações reais, ou seja, no cotidiano dos serviços, como evidenciado no estudo, torna a aprendizagem bem sucedida, contribuindo para que o estudante se torne crítico e reflexivo. Desse modo, podem tornar concreto na realidade o que apreenderam da teoria e, ao trazerem suas vivências, ampliam seus horizontes de possibilidades na busca do saber. Em consonância com esse processo de construção, os docentes necessitam repensar o modo como estão trabalhando o espaço de autonomia dos estudantes, considerando-os e respeitando-os em sua trajetória de aprendizagem. ${ }^{10}$

No cotidiano dos serviços, o docente, ao desenvolver atividades do enfermeiro, pode se tornar para o estudante um ideal de profissional em decorrência de sua atuação, logo, é indispensável que o docente e os estudantes se comprometam com os campos de práticas e não simplesmente compreendam esses cenários como algo externo ao seu quefazer cotidiano. Nesse contexto, a relação pedagógica se torna também um ponto de aprendizagem quando faz a conexão entre teoria e prática, estimula a participação do estudante e relaciona ensino, aprendizagem e vida real. ${ }^{11-12}$

Existe uma preocupação por parte dos docentes em estimular que o estudante desenvolva atitudes de acordo com o exercício profissional e na medida em que o estudante avança no curso vai se aproximando da prática do enfermeiro e estabelecendo melhor a relação entre teoria e prática, tornando o processo de ensino-aprendizagem mais fácil. ${ }^{9}$ As estratégias de ensino-aprendizagem são aspectos fundamentais na atuação do docente, todavia o sucesso de determinada estratégia está na dependência da integração de fatores relacionados tanto ao professor quanto ao estudante, fatores estes que envolvem motivação, conhecimento, persistência, interesse e respeitos às diferenças. ${ }^{13}$

Pensar em estratégias para motivar a aprendizagem sobre o princípio da integralidade, tendo como pilar o ensino prático reflexivo, não comporta uma formação voltada para a racionalidade técnica, 
na qual o conhecimento profissional dará conta apenas de responder a problemas instrumentais. Os problemas do contexto da prática não se apresentam aos profissionais com estruturas bem delineadas necessitando de habilidades, como o talento artístico profissional para resolvê-los. O desenvolvimento dessa competência foi uma fragilidade encontrada no estudo, assim, o processo de construção e valorização dos saberes e experiências da prática requerem a criação de inúmeras estratégias e planejamentos que viabilizem a construção dialógica entre mundo da academia e do serviço. ${ }^{3,8}$

É necessário adotar a epistemologia da prática reflexiva na formação do enfermeiro, a qual está sustentada pelos seguintes pilares: o conhecimento na ação, refletir na ação, reflexão sobre a ação e a reflexão sobre a reflexão na ação. ${ }^{3}$

O conhecimento na ação é caracterizado como um ato espontâneo que permite o desenvolvimento de tarefas rotineiras, de execução e sequências fáceis de atividades, sem que necessariamente precisemos pensar a respeito. O refletir na ação que é o momento onde encontramos um resultado inesperado no desenvolvimento da ação, e temos a possibilidade de interferir nessa ação. Esses dois momentos são realizados sem que necessariamente haja uma descrição verbal sobre o que se esteja fazendo. Na medida em que refletimos sobre a reflexão na ação passada, realizamos a reflexão sobre a ação, a qual permite modificar uma ação futura. A reflexão sobre a reflexão na ação contribui para a construção de conhecimentos do profissional, propiciando compreender problemas futuros ou descobrir novas soluções. ${ }^{3}$

A cultura de aprendizagem comprometida com a reflexão é uma forma valiosa de ajudar as enfermeiras a darem sentido a sua prática. ${ }^{14}$ Contudo, o processo de reflexão no contexto da sala de aula e nos serviços, nem sempre avança na cadeia de reflexão, ou seja, a reflexão na ação se transforma em reflexão sobre a ação. Todavia, existe um movimento por parte dos docentes, conforme mencionado neste estudo, para criar possibilidades de ensinar na integralidade, estabelecendo um processo de pensar e fazer que considere este princípio no cuidado à saúde e nas relações estabelecidas durante a formação.

Na relação pedagógica na formação do enfermeiro, o conhecimento na ação se transforma em reflexão na ação quando não ocorre dentro dos limites esperados, levando à reflexão sobre os motivos que geraram as situações vivenciadas. Estes momentos podem ocorrer em todos os contextos de ensino-aprendizagem, no entanto, quando al- mejamos um ensino prático-reflexivo, necessitamos que a reflexão na ação seja potencializada também na relação pedagógica. $\mathrm{O}$ docente imbuído desse pressuposto pedagógico, expressa uma prática reflexiva em suas próprias ações e estimula o estudante a também refletir sobre suas ações.

Nesse sentido, observou-se no estudo que, quando o docente cria possibilidades para que se avance no processo de reflexão, saindo do conhecimento na ação para a reflexão na ação, e posteriormente para a reflexão sobre a ação, o processo de ensino aprendizagem quebra a lógica da racionalidade técnica e se transforma em prática reflexiva, abrindo um leque de ações na perspectiva pedagógica do princípio da integralidade.

A enfermagem não é somente consumidora, mas também produtora de conhecimento através do enfrentamento de situação problemáticas vivenciadas na prática. Desse modo, além de aplicar as regras dos protocolos, os estudantes devem aprender as maneiras de questionar a conduta dos enfermeiros quando se deparam com situações instáveis, ambíguas e pouco claras no cotidiano da prática. $\mathrm{O}$ ensino-aprendizagem só se torna acessível quando se realiza a reflexão na ação. ${ }^{15}$

A partir deste entendimento, é possível afirmar que o exercício reflexivo sobre a aplicação do princípio integralidade na formação do enfermeiro deve ser alicerçado de modo coletivo, construído por vivências da prática acadêmica e por reflexões sobre a realidade. Esta construção instiga mudanças nas práticas de saúde e amalgama as relações estabelecidas durante o processo formativo do enfermeiro, envolvendo os sujeitos da academia, serviço e população. ${ }^{4}$

Na formação do enfermeiro e no próprio exercício profissional da enfermagem, entende-se que o diálogo está diretamente relacionado à capacidade de refletir sobre a construção de conhecimentos e o processo de cuidar. Nesse sentido, se transforma em um momento dialógico envolvendo todos os sujeitos, incentivando o estudante a agir com responsabilidade, avaliando e modificando sua prática acadêmica, bem como capacitando-o para exercer a sua profissão com maior qualificação e respeito ao usuário do serviço de Saúde. ${ }^{16}$

As situações vivenciadas no contexto do serviço colocam o docente em uma posição de desafio, pois este necessita encontrar estratégias pedagógicas que favoreçam a adaptação e a execução de ações concretas em um cenário com governabilidade limitada como apontado pelos docentes. ${ }^{17} \mathrm{O}$ discente ao trazer para o contexto da sala de aula experiências 
reais de sua vida profissional enriquece a discussão, e consequentemente, o processo de ensino aprendizagem. Contudo, exige do docente a capacidade de articular estes conhecimentos com as práticas atuais recomendadas nas políticas publicas de saúde e educação, estimulando no discente a reflexão em suas ações e sobre estas, construindo assim, um corpo de conhecimentos de novas ações. ${ }^{18}$

A relação pedagógica, ao estimular o desenvolvimento do talento artístico diante de situações incertas e conflituosas, prepara o futuro enfermeiro para lidar com as experiências de cuidados que requerem respostas que escapam aos cânones da racionalidade técnica.

No espaço de sala de aula, existe uma riqueza de enunciados, discursos e linguagens, que, ao ser explorado pelo professor durante sua interação com os estudantes, e mediante a adoção de estratégias de ensino-aprendizagem, contribui para o melhor aproveitamento dos conteúdos abordados no contexto teórico. ${ }^{19}$ Neste ínterim, o uso da reflexão na ação em sala de aula já foi comprovado como essencial para suprir as lacunas da educação para a prática e incorporar novas propostas pedagógicas para fortalecer a preparação educacional dos estudantes de enfermagem para a alta qualidade e competência no atendimento dos usuários e seus familiares. ${ }^{20}$

Para uma abordagem pedagógica que incorpora a prática reflexiva, o professor deve realizar uma reflexão constante sobre sua prática docente, sobre os objetivos do processo de ensino-aprendizagem, e promover o fortalecimento das informações debatidas na sala de aula, (re)significando conceitos, criando oportunidades de aprendizados que contribuam para o fortalecimento da relação pedagógica e desenvolvimento do talento artístico profissional. ${ }^{19}$ Este movimento de reflexão, reflexão sobre a ação e reflexão sobre a reflexão na ação conformam uma prática que contribui para a integralidade.

A adoção de práticas pedagógicas ativas pelos participantes da pesquisa considera o estudante como ser humano em formação e o docente como facilitador deste processo, estimula uma prática refletida que assegure ao estudante desenvolver competências e habilidades que estejam de acordo com as políticas nacionais de saúde e educação voltadas para o interesse da população brasileira. ${ }^{21}$ Contudo, é salutar que o docente reflita sobre sua formação permanente para além do desenvolvimento base para o ensino, proporcionando mudanças no modo de pensar e no fazer docente, tanto no nível individual como no coletivo. ${ }^{22}$

A reflexão do professor sobre seu próprio desempenho ou sobre o desempenho do estudante, bem como a reflexão do estudante sobre seu próprio desempenho, ou sobre o desempenho do professor podem contribuir para que uma descrição saliente diferenças, explicite conexões de um conjunto longo e rápido de ações de uma demonstração, ou revele o entendimento que informa variações superficiais no processo de ensino-aprendizagem. ${ }^{3}$

Ao partirmos destes princípios, certamente, conseguiremos dar voz ao sujeito, ouvindo e atendendo suas necessidades de saúde e encontraremos estratégias para enfrentar as situações incertas encontradas na prática. Nesse sentido, durante a formação o estudante deve ser estimulado a desenvolver o talento artístico para que consiga se construir profissionalmente como um enfermeiro que está capacitado para buscar respostas diante das demandas incertas e complexas de saúde.

Desenvolver o talento artístico e cuidar na perspectiva da integralidade é um caminho que emana da relação pedagógica e, portanto, não pode ser tratado paralelo a esta. Assim, o estudante, ao vivenciar uma relação que estimule estes princípios pedagógicos durante a graduação, tem mais possibilidade de aplicá-los durante e após seu processo de formação. A formação ${ }^{4}$ dos profissionais de saúde ancorada na integralidade requer a inclusão deste princípio também nas posturas pedagógicas, percebendo o estudante como um ser em formação reconhecido na sua integralidade.

\section{CONCLUSÃO}

Os elementos da relação pedagógica no ensino prático-reflexivo que caracterizem a aprendizagem a partir do princípio da integralidade durante a formação do enfermeiro estão relacionados à conexão teoria e prática, ao desenvolvimento do talento artístico profissional e ao processo de reflexão na e sobre a ação.

A relação pedagógica tem papel fundamental para "alinhavar" teoria e prática, estimulando o estudante a refletir sobre aprendido na articulação entre os conhecimentos teóricos e o campo da prática. Todavia, embora tivessem esta articulação pouco respaldada nos planos de ensino, os docentes demonstraram compromisso e se sentiam desafiados para estimular esta competência do estudante, tanto no contexto teórico como no prático.

O processo de conhecer e refletir na ação precisa ser estimulado para que se transforme mais frequentemente em reflexão sobre a ação e reflexão sobre a reflexão na ação. Assim, quebra-se a lógica 
de um ensino pautado na racionalidade técnica e aproxima-se de uma epistemologia da prática reflexiva que abre possibilidade para ações na perspectiva da integralidade.

A relação pedagógica no curso necessita criar possibilidades para formar profissionais competentes para atuar diante de situações incertas e conflituosas encontradas nos serviços de saúde. $\mathrm{O}$ desenvolvimento desta competência e habilidade está diretamente relacionado ao processo de reflexão na ação e sobre a ação, propiciando o desenvolvimento do talento artístico profissional.

Evidencia-se que estes elementos caracterizadores de um ensino na perspectiva da integralidade são muito novos, ao se considerar que a formação em enfermagem tem sua base construída na racionalidade técnica. Nesse sentindo, entende-se que, embora tenhamos políticas públicas de educação e de saúde que quebrem este paradigma, ainda estamos construindo coletivamente novas possibilidades pedagógicas para atender tanto as necessidades de saúde da população brasileira como as demandas da própria formação em saúde.

\section{AGRADECIMENTOS}

Ao Conselho Nacional de Desenvolvimento científico e tecnológico (CNPQ) pelo apoio financeiro. Ao Laboratório de Pesquisa e Tecnologia em Educação em Enfermagem e Saúde - EDEN pelo compartilhamento de saberes.

\section{REFERÊNCIAS}

1. Erdmann A, Fernandes JD, Teixeira GA. Panorama da educação em enfermagem no Brasil: graduação e pós-graduação. Enferm foco. 2011; 2(3):89-93.

2. Ferla JBS. Ênfase nas relações interpessoais na formação do enfermeiro sob o paradigma éticohumanista. Trab Educ Saúde [Internet]. 2013 [cited 2015 sep 05]; 11(3):633-57. Available from: http:// www.scielo.br/pdf/tes/v11n3/v11n3a10.pdf

3. Schön DA. Educando o profissional reflexivo: um novo design para o ensino e a aprendizagem. Porto Alegre (RS): Artmed; 2000.

4. Lima MM, Reibnitz KS, Prado MLdo, Kloh D. Comprehensiveness as a pedagogical principle in nursing education. Texto e Contexto Enferm [Internet]. 2013 [cited 2015 Dec 10]; 22(1):106-13. Available from: http:/ / www.scielo.br/pdf/tce/v22n1/13.pdf

5. Minayo MCS. O desafio do conhecimento: pesquisa qualitativa em saúde. $12^{\mathrm{a}}$ ed. São Paulo: Hucitec; 2010.

6. Kloh D. Reibnitz KS, Boehs AE, Wosny AM. The principle of integrality of care in the politicalpedagogical projects of nursing programs. Rev Latino-
Am Enfermagem [Internet]. 2014 [cited 2014 Nov 14]; 22(4): Available from: http://www.scielo.br/pdf/ rlae/v22n4/pt_0104-1169-rlae-0104-1169-3381-2469. pdf

7. Jiménez TL, Morán Peña L. Evaluación de una intervención educativa basada en el constructivismo en alumnas de enfermería de una universidad pública mexicana. Investigación y Educación en Enfermería [internet]. 2015 [cited 2017 Mar 08]; 33(3):432-9. Available from: https://dx.doi.org/10.17533/udea. iee.v33n3a06

8. Saippa-Oliveira G, Fernandez VS, Koifman L. Trabalho e formação: diálogos necessários para a construção de práticas do cuidado. In: Pinheiro R, Silva Junior AG. Por uma sociedade cuidadora. Rio de Janeiro: CEPESC; 2010. P. 297-312.

9. Paim AS, Iappe NT, Rocha DLB. Metodologias de ensino utilizadas por docentes do curso de enfermagem: enfoque na metodologia problematizadora. Enferm Glob [Internet]. 2015 [cited 2016 Mar 02]; 14(37):136-52. Available from: http:// scielo. isciii.es $/$ scielo.php?script $=$ sci_arttext\&pid=S169561412015000100007\&lng=pt

10. Fernandes MFP, Freitas GF. A construção do conhecimento do graduando de enfermagem: uma abordagem ético-social. Rev Bras Enferm. 2007; 60(1):62-7.

11. Zani AV, Nogueira MS. Incidentes críticos do processo ensino-aprendizagem do curso de graduação em enfermagem, segundo a percepção de estudantes e docentes. Rev Latino-Am Enfermagem [Internet]. 2006; [cited 2015 Feb 08]14(5):742-8. Available from: http://www.scielo.br/pdf/rlae/v14n5/ pt_v14n5a16.pdf

12. Johnson-Farmer B, Frenn M. Teaching excellence: what great teachers teach us. J Prof Nurs [Internet]. 2009 [cited 2016 Mar 30]; 25(5):267-72. Available from: http://www.professionalnursing.org/article/S87557223(09)00030-1/fulltext

13. Moura ECC, Mesquita LFC. Estratégias de ensinoaprendizagem na percepção de graduandos de enfermagem. Rev Bras Enferm. 2010; 63(5):793-8.

14. Bulman C, Lathlean J, Gobbi M. The concept of reflection in nursing: qualitative findings on student and teacher perspectives. Nurse Educ Today [Internet]. 2012 [cited 2016 Mar 30]; 32(5):e8-e13. Available from: http://www.sciencedirect.com/ science/article/pii/S0260691711002693?via\%3Dihub

15. Moya JLM, Parra SC. La enseñanza de la enfermería como una práctica reflexiva. Texto contexto - enferm. [Internet]. 2006 [cited 2016Mar 30]; 15(2): 303-11. Available from: http://www.scielo.br/pdf/tce/ v15n2/a14v15n2.pdf

16. Alves EATD, Cogo ALP. Percepção de estudantes de enfermagem sobre o processo de aprendizagem em ambiente hospitalar. Rev Gaúcha Enferm. [Internet]. 2014 [cited 2016 Mar 30]; 35(1):102-9. Available from: 
http://www.scielo.br/pdf/rgenf/v35n1/pt_19831447-rgenf-35-01-00102.pdf

17. Llapa-Rodríguez EO,Carvalho TS, Gois CFL, Guimarães AMDN. Vivencias de los estudiantes de pregrado con las asignaturas de administración de enfermería. Investigación y Educación en Enfermería [Internet]. 2012 [cited 2016 Mar 01]; 30(1):86-94. Available from: http://www.scielo. org.co $/$ scielo.php?script=sci_arttext\&pid $=$ S012053072012000100010\&lng=en\&tlng $=\mathrm{es}$

18. Tafner Daniela Priscila Oliveira do Vale, Reibnitz Kenya Schmidt, Lazzari Daniele Delacanal. Aplicação do princípio da integralidade nos cursos técnicos de enfermagem das escolas da rede SUS. Texto e Contexto Enferm. [Internet]. 2016 [cited 2017 Mar 28]; 25(4):e3470015. Available from: http://dx.doi. org/10.1590/0104-07072016003470015

19. Costa AJ, Santos MSS, Santos NMP. Reflexões sobre a intermediação da linguagem na relação entre professor e estudante de graduação em enfermagem. Reme Rev. min. enferm. [Internet]. 2006 [cited 2017 Jan 10]; 10(2):191-7. Available from: http:/ / reme.org.br/ artigo/detalhes/407

20. Glynn D M. Clinical Judgment Development Using Structured Classroom Refl ective Practice: A Qualitative Study. J Nurs Educ 2012;51(3):134-9.

21. Silva MG, Fernandes JD, Teixeira GAS, Silva RMO. Contemporary formal nursing education process: challenges and perspectives. Texto e Contexto Enferm. [Internet]. 2014 [cited 2014 Dec 05]; 19(1). Available from: http://www.scielo.br/pdf/tce/v19n1/ v19n1a21.pdf

22. Menegaz JC, Backes VMS, Medina JL, Prado ML, Canever BP. Pedagogical practices of good nursing, medicine and dentistry professors from the students' perception. Texto Contexto Enferm [Internet]. 2015 [cited 2017 Feb 14]; 24(3):629-36. Available from: https://dx.doi.org/10.1590/0104-07072015002790014 